\title{
Aminoacid zwitterions in solution: Geometric, energetic, and vibrational analysis using density functional theory-continuum model calculations
}

\author{
Francisco R. Tortonda, Juan-Luis Pascual-Ahuir, Estanislao Silla, ${ }^{\text {a) }}$ \\ and Iñaki Tuñón \\ Departamento de Química Física, Universidad de Valencia, 46100 Burjasot (Valencia), Spain \\ Francisco J. Ramírez \\ Departamento de Química Física, Universidad de Málaga, 29071 Málaga, Spain
}

(Received 5 March 1998; accepted 31 March 1998)

\begin{abstract}
Glycine and alanine aminoacids chemistry in solution is explored using a hybrid three parameters density functional (B3PW91) together with a continuum model. Geometries, energies, and vibrational spectra of glycine and alanine zwitterions are studied at the B3PW91/6-31+G** level and the results compared with those obtained at the HF and MP2/6-31+ $\mathrm{G}^{* *}$ levels. Solvents effects are incorporated by means of an ellipsoidal cavity model with a multipolar expansion (up to sixth order) of the solute's electrostatic potential. Our results confirm the validity of the B3PW91 functional for studying aminoacid chemistry in solution. Taking into account the more favorable scaling behavior of density functional techniques with respect to correlated $a b$ initio methods these studies could be extended to larger systems. (C) 1998 American Institute of Physics.
\end{abstract}

[S0021-9606(98)30126-9]

\section{INTRODUCTION}

Nowadays, continuum models have become one of the more popular methods of incorporating solvent effects into theoretical calculations on chemical systems. ${ }^{1}$ Although gas phase quantum calculations can frequently reproduce the essential features of chemical processes, there are a great variety of examples where the interaction with the surroundings must be explicitly included in order to obtain not only quantitative but also qualitative agreement with experiments. ${ }^{2}$ Aminoacid chemistry in solution is clearly one of these examples. It is well known that glycine molecule, the smallest aminoacid, is found in its neutral form (NE) in the gas phase, whereas the zwitterionic form ( $\mathrm{ZW})$ dominates in crystalline or aqueous media. ${ }^{3,4} \mathrm{Ab}$ initio calculations using flexible basis sets show that the zwitterionic form is not an energy minimum in vacuo and, consequently, if one wants to explore this aspect of the aminoacid chemistry, the interactions with the surroundings must be included into the calculations using, for example, continuum models. This is also the case of the analysis of the experimental infrared and Raman spectra of the aminoacids in solution. ${ }^{6}$ The assignment of the different fundamental vibrations often needs accurate calculations on the zwitterionic form of the aminoacid, which can not be obtained without the consideration of the solventinduced stabilization.

Previous theoretical works on aminoacids chemistry in solution have been usually restricted to the study of glycine zwitterion stability. Apart from statistical studies using classical potentials, ${ }^{7}$ quantum mechanical studies have been car-

\footnotetext{
a) Author to whom correspondence should be addressed. Electronic mail: Estanislao.Silla@uv.es
}

ried out using either the continuum model ${ }^{8-11}$ or small glycine-water clusters. ${ }^{9,11,12}$ In a pioneer work using the continuum model, Tomasi et al. ${ }^{8}$ showed that the electrostatic solute-solvent interactions stabilized the zwitterionic form, having this one an energy lower than the neutral form. Glycine zwitterion-water complexes have also been recently studied at ab initio levels. It seems that at least two water molecules are needed in order to transform the zwitterion into a local minimum. ${ }^{9,12}$ However, the great number of degrees of freedom makes difficult the study of solute-solvent clusters with enough number of solvent molecules to correctly represent the solution. Continuum models offer a way to simplify the treatment of the solvent, the calculations being only slightly more expensive than in vacuo. In our previous study ${ }^{9}$ on glycine zwitterion we showed that the longrange electrostatic interactions are needed to get a correct description of glycine energetics in solution and they are quite correctly incorporated into the continuum models. Continuum models have also been shown to be a useful tool for interpreting the vibrational spectra of aminoacid zwitterions in solution. ${ }^{9,13}$ Nowadays, there is a great variety of continuum solvation models ${ }^{1,14-17}$ and the selection of one of them must be based on the requirements of the system under study (semi-empirical or $a b$ initio, punctual calculation or geometry optimizations, correlation energy, frequencies analysis ...).

From previous studies on the stability of the isolated glycine zwitterion, ${ }^{5}$ it has been established that the correct description of the potential energy surface of the neutralzwitterion aminoacid conversion demands a considerable computational effort. Small-size basis sets are not enough to determine whether the zwitterionic form is a minimum or not on the Hartree-Fock gas phase potential energy surface 
(PES). In this sense, the presence of polarization functions on hydrogen atoms is crucial. ${ }^{5}$ Correlation energy seems also to play an important role. So, Ding et al. ${ }^{11}$ concluded that there is not a zwitterionic minimum on the gas phase potential energy surface computed with a correlated wave function. In our recent study about glycine zwitterion ${ }^{9}$ we showed that the complex of the zwitterion with a single water molecule is no longer a minimum when correlation energy is included at the second order of M $\phi$ ller-Plesset perturbation theory (MP2). However, when employing a continuum model the inclusion of correlation energy favors the zwitterionic form with respect to the neutral one, the former becoming the absolute minimum in solution, contrary to the results obtained at the Hartree-Fock level.

Thus moderate or large basis sets and correlation energy (for example, at the MP2 level) seem to be important factors to describe the zwitterion stability in solution. This kind of calculation can be nearly routinely made for glycine aminoacid but they can be very computationally demanding for larger aminoacids, especially if energy derivatives and force constants are required, and thus their application can be restricted to the smaller members of the series. Alternative methodologies are thus desirable. In this sense, density functional theory (DFT) methods explicitly include correlation energy and offer a way for obtaining accurate geometrical and thermodynamic data at a fraction of the computational cost of traditional correlated ab initio methods. ${ }^{18}$ This is due to the favorable scaling behavior of DFT methods, opening up the way to studies on larger systems. Density functional methods have been previously applied to the study of the gas phase potential energy surface of glycine and alanine. . $^{9,20}$ These studies show that standard density functional methods have some difficulties in reproducing the small energy differences among the different conformers found on the energy surface, but hybrid functionals, which include density gradient corrections and some Hartree-Fock exchange, approach the quality of MP2 calculations consuming less computational time. Promising results have also been obtained in the description of proton transfer processes when using such hybrid functionals. ${ }^{21}$ It has also been recently shown that density functional methods in combination with the scaled quantum mechanical $(\mathrm{SQM})^{22}$ procedure successfully reproduce the vibrational spectra of a great variety of molecules, offering a useful tool for the interpretation and the assignment of the spectra of other systems.

In this paper we apply a density functional method in conjunction with a continuum solvation model to the study of the stability and vibrational dynamics of glycine and alanine zwitterions in solution. The results obtained with this method are compared with $a b$ initio methods such as Hartree-Fock and MP2 calculations as well as with experimental results. We can state in advance that density functional methods give results of good quality and that together with the use of a continuum model can be very useful to predict and analyze the behavior of larger aminoacids in solution.

\section{METHODOLOGY}

$A b$ initio calculations have been carried out at the HF and MP2 levels using the $6-31+\mathrm{G}^{* *}$ basis set, ${ }^{23}$ which includes polarization functions on all the atoms and diffuse functions on all the atoms but the hydrogens. Density functional theory calculations (DFT) have been made using the hybrid functional B3PW91. ${ }^{24}$ This functional has been selected because it has been shown to behave better than the more usual hybrid B3LYP functional in the calculation of gas phase acidities. ${ }^{25}$ Molecular geometries have been optimized at the respective levels using the Berny's and redundant coordinates algorithms. ${ }^{26,27}$

Solute-solvent electrostatic interaction has been simulated employing the continuum model of Rivail et al. ${ }^{14,28,29}$ In this model, the liquid is assimilated to a continuum characterized by a dielectric constant ( 78.4 for water). The quantum system is then placed in an ellipsoidal cavity whose volume is obtained by means of an empirical relation. ${ }^{30}$ The electrostatic interaction is calculated using a multipolar moment expansion (up to sixth order) and introduced in the Hamiltonian of the system. The analytical derivatives of this electrostatic term have been derived leading to an efficient geometry optimization procedure. ${ }^{31}$ Cartesian force constants in solution have been calculated at the fully optimized geometry using analytical second derivatives. ${ }^{32}$ This continuum model is probably the best choice if analytical force constants are required. It must be emphasized here that the more simplified Onsager's model ${ }^{33}$ can lead to severe underestimations of the solute-solvent electrostatic interaction energy. For example, in the glycine zwitterion the dipolar term represents around $80 \%$ of the total interaction free energy, and $70 \%$ in the case of alanine. For larger aminoacids the participation of the dipolar term can be smaller (about $40 \%$ in the glutamine aminoacid). ${ }^{34}$ All the calculations have been carried out using the GAUSSIAN94 package of programs. ${ }^{35}$ For consideration of continuum solvent effects an extra link has been added. ${ }^{36}$

The cartesian force constants were transformed into a set of nonredundant local symmetrical internal coordinates, defined according to the Pulay methodology. ${ }^{37}$ This allows for a more useful description of the vibrational potential energy, making comparisons for similar molecules easier. Wave numbers and normal coordinates were calculated by the Wilson FG matrix method. ${ }^{38}$

\section{RESULTS}

\section{A. Geometries}

The neutral and zwitterionic conformations of glycine and alanine studied in solution and the atom numbering are shown in Fig. 1 together with the transition structure connecting both structures. The neutral forms of the glycine and alanine present a large number of possible conformers ${ }^{19,20,39}$ but the one shown in the Fig. 1 is the absolute minimum in solution both for glycine and alanine aminoacids. ${ }^{9,40}$ These neutral structures are different from the absolute minima of the gas phase potential energy surface of glycine and alanine, but because of their large dipole moments, they become more stable than any other in solution. For the zwitterionic 


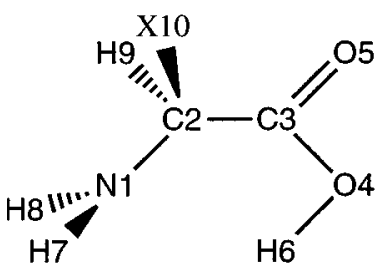

NE

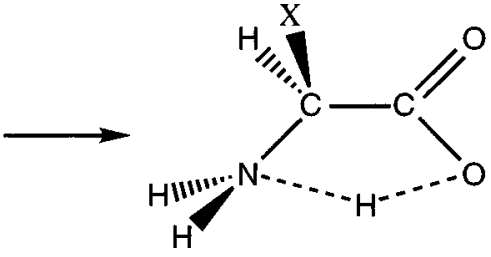

TS

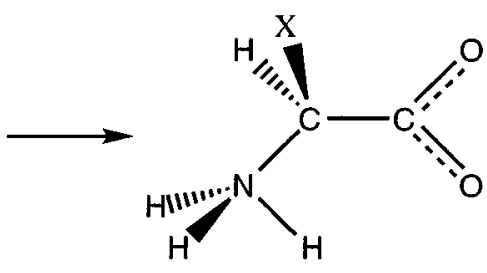

ZW

FIG. 1. Schematic representation and atomic numbering for the neutral, zwitterionic, and transition structure of the aminoacids here studied.

form of the two aminoacids we have not located any other minima structures in agreement with a previous study carried out in the gas phase. ${ }^{5}$ The transition structure corresponds to the intramolecular proton transfer from neutral to zwitterionic aminoacid. From our previous results, it seems that the intramolecular proton transfer is energetically more favorable than the intermolecular proton transfer where a water solvent molecule directly participates in the transition structure. ${ }^{9}$

Selected geometrical parameters of the three structures studied in solution $(\mathrm{NE}, \mathrm{TS}$, and $\mathrm{ZW})$ for glycine $(\mathrm{X}=\mathrm{H})$ and alanine $\left(\mathrm{X}=\mathrm{CH}_{3}\right)$ are given in Table I. The geometrical parameters obtained for neutral glycine at the MP2 and B3PW91 levels are very close. As expected from the lack of correlation energy carbon-oxygen distances obtained at the HF level are too short. Another geometrical difference, with important consequences in the proton transfer process is the N1-H6 distance, much larger at the HF level $(2.031 \AA)$ than at the MP2 (1.821 $)$ ) or B3PW91 (1.762 $\AA)$ levels. This seems to be a consequence of the loss of planarity among the $\mathrm{H} 1-\mathrm{N}-\mathrm{C}-\mathrm{C}-\mathrm{O} 2$ atoms at the $\mathrm{HF}$ level. It has been previ-

TABLE I. Bond lengths (in $\AA$ ), bond angles, and dihedral angles (in degrees) for the structures of glycine $(\mathrm{X}=\mathrm{H})$ and alanine $(\mathrm{X}=\mathrm{Me})$ studied at the different computational levels used.

\begin{tabular}{|c|c|c|c|c|c|c|c|c|c|}
\hline \multicolumn{10}{|c|}{$\mathrm{X}=\mathrm{H}$} \\
\hline & \multicolumn{3}{|c|}{$\mathrm{NE}$} & \multicolumn{3}{|c|}{ TS } & \multicolumn{3}{|c|}{$\mathrm{ZW}$} \\
\hline & $\mathrm{HF}$ & MP2 & B3PW91 & $\mathrm{HF}$ & MP2 & B3PW91 & $\mathrm{HF}$ & MP2 & B3PW91 \\
\hline $\mathrm{C} 2 \mathrm{~N} 1$ & 1.449 & 1.461 & 1.461 & 1.471 & 1.473 & 1.476 & 1.493 & 1.495 & 1.496 \\
\hline $\mathrm{C} 2 \mathrm{C} 3$ & 1.521 & 1.526 & 1.529 & 1.534 & 1.537 & 1.541 & 1.540 & 1.546 & 1.551 \\
\hline $\mathrm{C} 3 \mathrm{O} 5$ & 1.196 & 1.226 & 1.217 & 1.208 & 1.235 & 1.227 & 1.229 & 1.258 & 1.245 \\
\hline $\mathrm{C} 3 \mathrm{O} 4$ & 1.315 & 1.341 & 1.331 & 1.277 & 1.313 & 1.300 & 1.241 & 1.274 & 1.267 \\
\hline $\mathrm{C} 2 \mathrm{X}^{10}$ & 1.084 & 1.089 & 1.094 & 1.080 & 1.087 & 1.092 & 1.082 & 1.087 & 1.090 \\
\hline O4H6 & 0.957 & 0.999 & 1.007 & 1.232 & 1.207 & 1.244 & 2.150 & 2.006 & 1.813 \\
\hline N1H6 & 2.024 & 1.821 & 1.762 & 1.255 & 1.313 & 1.275 & 1.010 & 1.031 & 1.048 \\
\hline $\mathrm{N} 1 \mathrm{C} 2 \mathrm{C} 3$ & 111.7 & 109.8 & 109.5 & 103.9 & 104.4 & 104.4 & 110.7 & 109.5 & 108.0 \\
\hline $\mathrm{O} 5 \mathrm{C} 2 \mathrm{C} 3$ & 122.7 & 123.8 & 124.0 & 121.5 & 122.3 & 121.7 & 115.0 & 115.3 & 115.6 \\
\hline $\mathrm{O} 4 \mathrm{C} 2 \mathrm{C} 3$ & 115.7 & 113.9 & 112.8 & 110.4 & 110.8 & 110.4 & 115.7 & 116.1 & 114.9 \\
\hline N1H6O4 & 120.0 & 128.9 & 128.9 & 140.8 & 141.3 & 141.1 & 109.7 & 117.5 & 124.8 \\
\hline $\mathrm{N} 1 \mathrm{C} 2 \mathrm{C} 3 \mathrm{O} 4$ & 11.4 & 0.0 & 0.0 & 0.0 & 0.0 & 0.0 & 22.6 & 16.8 & 0.0 \\
\hline \multirow[t]{4}{*}{$\mathrm{C} 2 \mathrm{C} 3 \mathrm{~N} 1 \mathrm{H} 6$} & 9.1 & 0.0 & 0.0 & 0.0 & 0.0 & 0.0 & 29.5 & 18.0 & 0.0 \\
\hline & \multirow{2}{*}{\multicolumn{6}{|c|}{$\mathrm{X}=\mathrm{Me}$}} & \multirow{2}{*}{\multicolumn{3}{|c|}{$\mathrm{ZW}$}} \\
\hline & & $\mathrm{NE}$ & & & & & & & \\
\hline & $\mathrm{HF}$ & MP2 & B3PW91 & $\mathrm{HF}$ & MP2 & B3PW91 & $\mathrm{HF}$ & MP2 & B3PW91 \\
\hline $\mathrm{C} 2 \mathrm{~N} 1$ & 1.453 & 1.465 & 1.467 & 1.478 & 1.479 & 1.484 & 1.505 & 1.504 & 1.510 \\
\hline $\mathrm{C} 2 \mathrm{C} 3$ & 1.527 & 1.528 & 1.538 & 1.541 & 1.542 & 1.549 & 1.548 & 1.553 & 1.559 \\
\hline $\mathrm{C} 3 \mathrm{O} 5$ & 1.197 & 1.226 & 1.218 & 1.209 & 1.235 & 1.228 & 1.233 & 1.264 & 1.251 \\
\hline $\mathrm{C} 3 \mathrm{O} 4$ & 1.316 & 1.342 & 1.330 & 1.277 & 1.314 & 1.301 & 1.240 & 1.271 & 1.263 \\
\hline $\mathrm{C} 2 \mathrm{X} 10$ & 1.535 & 1.531 & 1.532 & 1.529 & 1.527 & 1.528 & 1.532 & 1.527 & 1.530 \\
\hline O4H6 & 0.956 & 0.996 & 1.009 & 1.221 & 1.193 & 1.221 & 2.320 & 2.310 & 2.059 \\
\hline N1H6 & 2.068 & 1.857 & 1.750 & 1.292 & 1.327 & 1.292 & 1.008 & 1.023 & 1.031 \\
\hline $\mathrm{N} 1 \mathrm{C} 2 \mathrm{C} 3$ & 109.3 & 107.9 & 107.5 & 102.6 & 103.1 & 103.1 & 108.3 & 107.9 & 106.7 \\
\hline $\mathrm{O} 5 \mathrm{C} 2 \mathrm{C} 3$ & 123.0 & 124.0 & 124.0 & 121.7 & 122.5 & 121.9 & 115.7 & 116.0 & 116.2 \\
\hline $\mathrm{O} 4 \mathrm{C} 2 \mathrm{C} 3$ & 115.9 & 114.1 & 113.1 & 110.7 & 111.0 & 110.9 & 115.6 & 116.0 & 115.0 \\
\hline N1H6O4 & 117.7 & 126.2 & 130.4 & 140.7 & 141.0 & 141.1 & 103.0 & 105.4 & 114.7 \\
\hline $\mathrm{N} 1 \mathrm{C} 2 \mathrm{C} 3 \mathrm{O} 4$ & 25.6 & 20.6 & 12.6 & 9.7 & 12.5 & 9.6 & 41.7 & 44.7 & 35.2 \\
\hline $\mathrm{C} 2 \mathrm{C} 3 \mathrm{~N} 1 \mathrm{H} 6$ & 19.7 & 16.3 & 10.0 & 6.9 & 9.4 & 7.0 & 44.6 & 42.9 & 29.7 \\
\hline
\end{tabular}


ously established that the $\mathrm{C}_{s}$ structure (which has N1-C2$\mathrm{C} 3-\mathrm{O} 4$ and $\mathrm{H} 6-\mathrm{N} 1-\mathrm{C} 2-\mathrm{C} 3$ dihedral angles equal to zero) is a transition state in the gas phase, connecting the two symmetrical $\mathrm{C}_{1}$ structures ${ }^{41,42}$ with an energy barrier of about $0.3 \mathrm{kcal} / \mathrm{mol}$ at the $\mathrm{HF} / 6-311 \mathrm{G}^{* *}$ level $^{40}$ and only $0.1 \mathrm{kcal} /$ mol when correlation energy is included at the MP2 level. ${ }^{41,42}$ Solvent effects seem to diminish the force constant associated with the $\mathrm{N} 1-\mathrm{C} 2-\mathrm{C} 3-\mathrm{O} 4$ dihedral angle. So, the completely planar $\left(\mathrm{C}_{s}\right)$ structure has an energy only 0.03 $\mathrm{kcal} / \mathrm{mol}$ higher than the nonplanar $\left(\mathrm{C}_{1}\right)$ one at the HF level and an imaginary frequency of $47 \mathrm{~cm}^{-1}$. Conversely, geometry optimizations at the MP2 and B3PW91 levels (i.e., including correlation energy) which were started from different $\mathrm{C}_{1}$ structures always led to the $\mathrm{C}_{s}$ one.

The transition structure of the intramolecular proton transfer is completely planar at the three computational levels used. This transition structure is more advanced in the reaction path at the HF and B3PW91 levels, with very similar N1-H6 and $\mathrm{O} 4-\mathrm{H} 6$ distances, than at the MP2 level where the NH1 distance is about $0.1 \AA$ larger than the O4-H6 one. The N1-H6-O4 angle is about 140 degrees in the transition structure, approaching the linear hydrogen bond, while it was of about 120-130 degrees in the neutral form. This angle decreases again in the zwitterion, reaching a value between 109-125 degrees depending on the computational level. The more important difference among the geometries obtained for the glycine zwitterion at each computational level is the $\mathrm{C}_{s}$ symmetry structure obtained at the B3PW91 level, contrary to the HF and MP2 results. At the $\mathrm{HF} / 6-31+\mathrm{G}^{* *}$ level, the zwitterionic $\mathrm{C}_{s}$ structure is a transition state in solution with an imaginary frequency of $82 \mathrm{~cm}^{-1}$ and an energy $0.23 \mathrm{kcal} / \mathrm{mol}$ higher than the two mirror image $\mathrm{C}_{1}$ structures. At the MP2 level, the differences are still smaller and the $\mathrm{C}_{1}$ structures are only $0.04 \mathrm{kcal} / \mathrm{mol}$ more stable than the $\mathrm{C}_{s}$ one. We have optimized a $\mathrm{C}_{1}$ zwitterionic structure at the B3PW91 level by keeping the N1$\mathrm{C} 2-\mathrm{C} 3-\mathrm{O} 4$ dihedral angle fixed to the MP2 value. The resulting structure was $0.18 \mathrm{kcal} / \mathrm{mol}$ less stable than the $\mathrm{C}_{s}$ one. As a consequence of the planarity of the B3PW91 zwitterionic structure the intramolecular $\mathrm{H6}-\mathrm{O} 4$ hydrogen bond is shorter at this computational level than at the HF and MP2 levels. In fact, the H6-O4 distance $(1.813 \AA)$ is shorter than at the HF $(2.150 \AA)$ and MP2 (2.006 $)$ levels. We have also found the same results using the B3LYP hybrid functional. In the zwitterionic form, both carbon-oxygen bond lengths are very close, the $\mathrm{C} 3-\mathrm{O} 4$ bond length being somewhat larger because of the presence of the hydrogen bond with H6. In fact, the difference between both carbon-oxygen distances at each computational level is inversely proportional to the $\mathrm{O} 4-\mathrm{H} 6$ one. The carbon-carbon and the carbonnitrogen bond lengths are larger in the zwitterion than in the neutral form of the glycine.

The geometrical description of the three structures (NE, $\mathrm{TS}$, and ZW) for the alanine aminoacid is very similar to that for glycine. The main difference with respect to the glycine results arise from the presence of the methyl group breaking the possible symmetry of the structures. Effectively, in the case of alanine neither the neutral, the transition structure or the zwitterionic form present coplanarity among the H6-
TABLE II. Relative energies (in $\mathrm{kcal} / \mathrm{mol}$ ) for the structures of glycine $(\mathrm{X}=\mathrm{H})$ and alanine $(\mathrm{X}=\mathrm{Me})$ studied at the different computational levels used.

\begin{tabular}{ccrrrrrrr}
\hline \hline & \multicolumn{3}{c}{$\mathrm{X}=\mathrm{H}$} & & \multicolumn{3}{c}{$\mathrm{X}=\mathrm{Me}$} \\
\cline { 2 - 4 } \cline { 6 - 8 } \cline { 6 - 8 } & $\mathrm{NE}$ & \multicolumn{1}{c}{$\mathrm{TS}$} & $\mathrm{ZW}$ & & $\mathrm{NE}$ & $\mathrm{TS}$ & $\mathrm{ZW}$ \\
\hline $\mathrm{HF} / 6-31+\mathrm{G}^{* *}$ & 0. & 11.04 & 2.29 & & 0. & 10.55 & -0.45 \\
$\mathrm{MP} 2 / 6-31+\mathrm{G}^{* *}$ & 0. & 2.39 & -1.15 & & 0. & 2.16 & -3.58 \\
$\mathrm{~B} 3 \mathrm{PW} 91 / 6-31+\mathrm{G}^{* *}$ & 0. & 1.93 & 0.90 & & 0. & 1.32 & -1.21 \\
\hline \hline
\end{tabular}

$\mathrm{N} 1-\mathrm{C} 2-\mathrm{C} 3-\mathrm{O} 4$ atoms at any of the computational levels here employed. Because of the hydrogen bond interaction, the transition structure is the closest to the planarity with $\mathrm{N} 1-\mathrm{C} 2-\mathrm{C} 3-\mathrm{O} 4$ dihedral angles ranging between 9 and 13 degrees, depending on the computational level. The intramolecular hydrogen bond $\mathrm{O} 4-\mathrm{H} 6$ is weaker in the zwitterionic form of the alanine than in the case of glycine. So, the O4-H6 distance is lengthened by $0.2-0.3 \AA$ with respect to the glycine zwitterion, depending on the computational level. Consequently, the N1-H6 bond lengths are somewhat shorter in the alanine zwitterion than in the glycine zwitterion.

\section{B. Energies}

Relative energies for the neutral (NE), zwitterionic (ZW), and transition structure (TS) conformations of glycine and alanine aminoacids in solution are shown in Table II. In a first examination of our results we can observe that the presence of a methyl group in alanine makes the zwitterionic structure more stable than the neutral one at all the computational levels used. This is not the case of glycine where only at the MP2/6-31+G** level the zwitterion is the more stable tautomeric form in solution by $1.15 \mathrm{kcal} / \mathrm{mol}$. The relative stabilisation produced by the methyl group in the alanine zwitterion with respect to the glycine zwitterion is $2.74,2.43$, and $2.11 \mathrm{kcal} / \mathrm{mol}$ at the HF, MP2, and B3PW91 levels, respectively. The energy barriers for the intramolecular proton transfer are somewhat smaller for alanine than for glycine at the three computational levels employed. Inclusion of correlation energy seems to be fundamental to correctly describe the proton transfer barrier. The energy barriers are approximately five times higher at the HF level than the corresponding values at the MP2 level. Calculations at the B3PW91 level are in general in good agreement with MP2 results both for proton transfer energy barriers and zwitterion relative energies. Our estimations of the stabilization energy for the tautomeric equilibrium between neutral and zwitterionic forms of glycine and alanine aminoacids at the HF, MP2 and B3PW91 levels are 2.29, -1.15 , and 0.90 $\mathrm{kcal} / \mathrm{mol}$ and $-0.45,-3.38$, and $-1.21 \mathrm{kcal} / \mathrm{mol}$, respectively. These relative free energies have not been obtained by direct experimental determination and estimations are only available for the case of the glycine aminoacid. An estimation for glycine based on the equilibrium constant for the ratio of the zwitterionic form to the neutral form in pure water at $298 \mathrm{~K}$ gives a relative free energy of $-7.27 \mathrm{kcal} / \mathrm{mol}^{43}$ with respect to the neutral form and an- 
TABLE III. Symmetrized Pulay coordinates used in this work for the vibrational analysis of glycine.

\begin{tabular}{clll}
\hline \hline Number $^{\mathrm{a}}$ & \multicolumn{1}{c}{ Coordinate $^{\mathrm{b}}$} & Symbol & \multicolumn{1}{c}{ Description } \\
\hline 1 & $r_{12}$ & $n(\mathrm{CN})$ & $\mathrm{CN}$ stretch \\
2 & $r_{23}$ & $n(\mathrm{CC})$ & $\mathrm{CC}$ stretch. \\
3 & $r_{34}$ & $n\left(\mathrm{CO}_{2}^{-}\right)$ & $\mathrm{CO}_{2}^{-}$stretch. \\
4 & $r_{35}$ & $n\left(\mathrm{CO}_{2}^{-}\right)$ & $\mathrm{CO}_{2}^{-}$stretch. \\
5 & $r_{29}+r_{210}$ & $n_{s}\left(\mathrm{CH}_{2}\right)$ & $\mathrm{CH}_{2}$ sym. stretch. \\
6 & $r_{29}-r_{210}$ & $n_{a}\left(\mathrm{CH}_{2}\right)$ & $\mathrm{CH}_{2}$ antisym. stretch. \\
7 & $r_{16}$ & $n\left(\mathrm{NH}^{2}\right)$ & $\mathrm{NH}_{3}^{+}$stretch. \\
8 & $r_{17}$ & $n\left(\mathrm{NH}^{2}\right.$ & $\mathrm{NH}_{3}^{+}$stretch. \\
9 & $r_{18}$ & $n\left(\mathrm{NH}^{2}\right.$ & $\mathrm{NH}_{3}^{+}$stretch. \\
10 & $2 b_{435}-b_{234}-b_{235}$ & $d\left(\mathrm{CO}_{2}^{-}\right)$ & $\mathrm{CO}_{2}^{-}$bending \\
11 & $b_{234}-b_{235}$ & $w\left(\mathrm{CO}_{2}^{-}\right)$ & $\mathrm{CO}_{2}^{-}$wagging \\
12 & $C_{3}$ out-of-plane bending & $g\left(\mathrm{OCO}_{2}\right)$ & $\mathrm{CO}_{2}^{-}$out-pl bending \\
13 & $5 b_{9210}-b_{123}$ & $d\left(\mathrm{CH}_{2}\right)$ & $\mathrm{CH}_{2}$ scissoring \\
14 & $5 b_{123}-b_{9210}$ & $d\left(\mathrm{CCN}^{2}\right)$ & skeletal bending \\
15 & $b_{329}-b_{3210}+b_{129}-b_{1210}$ & $r\left(\mathrm{CH}_{2}\right)$ & $\mathrm{CH}_{2}$ rocking \\
16 & $b_{329}+b_{3210}-b_{129}-b_{1210}$ & $w\left(\mathrm{CH}_{2}\right)$ & $\mathrm{CH}_{2}$ wagging \\
17 & $b_{329}-b_{3210}-b_{129}+b_{1210}$ & $t\left(\mathrm{CH}_{2}\right)$ & $\mathrm{CH}_{2}$ twisting \\
18 & $b_{617}+b_{618}+b_{718}-b_{216}-b_{217}-b_{218}$ & $d_{s}\left(\mathrm{NH}_{3}^{+}\right)$ & $\mathrm{NH}_{3}^{+}$antisym. bending \\
19 & $2 b_{718}-b_{617}-b_{618}$ & $d_{a}\left(\mathrm{NH}_{3}^{+}\right)$ & $\mathrm{NH}_{3}^{+}$antisym. bending \\
20 & $b_{617}-b_{618}$ & $d_{a}\left(\mathrm{NH}_{3}^{+}\right)$ & $\mathrm{NH}_{3}^{+}$sym. bending \\
21 & $2 b_{216}-b_{217}-b_{218}$ & $r\left(\mathrm{NH}_{3}^{+}\right)$ & $\mathrm{NH}_{3}^{+}$rocking \\
22 & $b_{217}-b_{218}$ & $r\left(\mathrm{NH}_{3}^{+}\right)$ & $\mathrm{NH}_{3}^{+}$rocking \\
23 & $\mathrm{~N}_{1}-\mathrm{C}_{2}$ torsion & $t\left(\mathrm{NH}_{3}^{+}\right)$ & $\mathrm{NH}_{3}^{+}$torsion \\
24 & $\mathrm{C}_{2}-\mathrm{C}_{3}$ torsion & $t\left(\mathrm{CO}_{2}^{-}\right)$ & $\mathrm{CO}_{2}^{-}$torsion \\
\hline \hline
\end{tabular}

${ }^{\mathrm{a}}$ Arbitrary numbering

${ }^{\mathrm{b}}$ The atomic numbering is defined in Fig. 1. $r_{i j}$ is the stretching vibration of the bond between atoms $i$ and $j$. $b_{i j k}$ is the in-plane bending vibration of the angle between atoms $i, j$, and $k . f_{i}$ is the out-of-plane bending vibration of the atom $i . t_{i j}$ is the torsion vibration with respect to the bond between atoms $i$ and $j$, which were defined as described in Refs. 47, 48.

other estimation based on thermodynamic cycles and summation method gives a relative free energy of $-7.67 \mathrm{kcal} / \mathrm{mol}^{44}$ The procedure employed in this last estimation implies the use of the summation method to obtain the solvation energy of some ions, which has been shown to produce large errors. ${ }^{45}$

The discrepancy between the experimental estimations and our theoretical values can be rationalized considering the different possible source of errors. First, our values are incomplete because of the lack of zero-point, thermal, dispersion-repulsion, and cavitation contributions to the relative free energy. It has been shown that the sum of thermal and dispersion-repulsion terms can favor the zwitterionic form of the glycine aminoacid by about $1.6 \mathrm{kcal} / \mathrm{mol}$ with respect to the neutral one in solution. ${ }^{1}$ Although cavitation energies could be expected to be of similar magnitude for zwitterionic and neutral glycine, a disminution of the cavity is expected in the zwitterion because of the contraction of the solvent shell as a consequence of a stronger solute-solvent interaction. In fact, by means of QM/MM calculations ${ }^{46}$ we have verified that the first peaks of the radial distribution functions (RDFs) of $\mathrm{N} 1$ and $\mathrm{O} 4$ atoms of the glycine zwitterion are shifted toward smaller distances by about $0.1 \AA$ when compared with the neutral glycine RDFs. This contraction can also affect the rest of the solute-solvent interaction energy terms. Second, the cavity model (ellipsoidal) here used can also underestimate the electrostatic stabilization of the zwitterion. In fact, we have carried out a punctual calcu- lation at the MP2 level using a molecular shaped cavity (by means of the PCM model ${ }^{15}$ ) and we have obtained a relative free energy of $-4.85 \mathrm{kcal} / \mathrm{mol}$, i.e., the zwitterion being 3.70 $\mathrm{kcal} / \mathrm{mol}$ more stable than with the ellipsoidal cavity. This result could be further refined taking into account the change in the cavity volume due to the contraction of the solvation shell around the zwitterion with respect to the neutral form. As said above, the use of the ellipsoidal cavity model is here justified because we are also interested in obtaining analytic second derivatives.

\section{Vibrational analysis}

We have obtained complete quadratic force fields for glycine and alanine zwitterions at the absolute minimal energy structures each, using both HF and B3PW91 levels. The force constants were transformed to the set of locally symmetrized internal coordinates listed in Tables III and IV. The results concerning frequencies, infrared intensities, and potential energy distribution (P.E.D.) are summarized in Tables $\mathrm{V}$ and VI for glycine and alanine, respectively, where the experimental frequencies and assignments were included. Finally, diagonal force constants for the two aminoacids studied are compared in Table VII.

In spite of the fact that some glycine frequencies are not available from experiments, because of the strong water absorptions, the results listed in Table $\mathrm{V}$ show that the B3PW91 set of data are significantly improved with respect 
TABLE IV. Symmetrized Pulay coordinates used in this work for the vibrational analysis of alanine.

\begin{tabular}{|c|c|c|c|}
\hline Number $^{\mathrm{a}}$ & Coordinate $^{\mathrm{b}}$ & Symbol & Description \\
\hline 1 & $r_{12}$ & $n(\mathrm{CN})$ & $\mathrm{CN}$ stretch \\
\hline 2 & $r_{23}$ & $n(\mathrm{CC})$ & CC stretch.. \\
\hline 3 & $r_{29}$ & $n(\mathrm{CC})$ & CC stretch.. \\
\hline 4 & $r_{34}$ & $n\left(\mathrm{CO}_{2}^{-}\right)$ & $\mathrm{CO}_{2}^{-}$stretch. \\
\hline 5 & $r_{35}$ & $n\left(\mathrm{CO}_{2}^{-}\right)$ & $\mathrm{CO}_{2}^{-}$stretch. \\
\hline 6 & $r_{210}$ & $n(\mathrm{CH})$ & $\mathrm{CH}$ stretch. \\
\hline 7 & $r_{16}$ & $n(\mathrm{NH})$ & $\mathrm{NH}_{3}^{+}$stretch \\
\hline 8 & $r_{17}$ & $n(\mathrm{NH})$ & $\mathrm{NH}_{3}^{+}$stretch \\
\hline 9 & $r_{18}$ & $n(\mathrm{NH})$ & $\mathrm{NH}_{3}^{+}$stretch \\
\hline 10 & $r_{911}+r_{912}+r_{913}$ & $n_{s}\left(\mathrm{CH}_{3}\right)$ & $\mathrm{CH}_{3}$ sym. stretch. \\
\hline 11 & $2 r_{911}-r_{912}-r_{913}$ & $n_{a}\left(\mathrm{CH}_{3}\right)$ & $\mathrm{CH}_{3}$ antisym. stretch. \\
\hline 12 & $r_{912}-r_{913}$ & $n_{a}\left(\mathrm{CH}_{3}\right)$ & $\mathrm{CH}_{3}$ antisym. stretch. \\
\hline 13 & $2 b_{435}-b_{234}-b_{235}$ & $d\left(\mathrm{CO}_{2}^{-}\right)$ & $\mathrm{CO}_{2}^{-}$bending \\
\hline 14 & $b_{234}-b_{235}$ & $w\left(\mathrm{CO}_{2}^{-}\right)$ & $\mathrm{CO}_{2}^{-}$wagging \\
\hline 15 & $c_{3}$ out of-plane bending & $g\left(\mathrm{OCO}^{-}\right)$ & $\mathrm{CO}_{2}^{-}$out-pl bending \\
\hline 16 & $2 b_{3210}-b_{1210}-b_{9210}$ & $d(\mathrm{CH})$ & $\mathrm{CH}$ bending \\
\hline 17 & $b_{1210}-b_{9210}$ & $\mathrm{~d}(\mathrm{CH})$ & $\mathrm{CH}$ bending \\
\hline 18 & $4 b_{321}-b_{329}-b_{921}$ & $d(\mathrm{CCN})$ & skeletal bending \\
\hline 19 & $4 b_{329}-b_{921}-b_{321}$ & $d(\mathrm{CCN})$ & skeletal bending \\
\hline 20 & $4 b_{921}-b_{321}-b_{329}$ & $d(\mathrm{CCN})$ & skeletal bending \\
\hline 21 & $b_{617}+b_{618}+b_{718}-b_{216}-b_{217}-b_{218}$ & $d_{s}\left(\mathrm{NH}_{3}^{+}\right)$ & $\mathrm{NH}_{3}^{+}$antisym. bending \\
\hline 22 & $2 b_{718}-b_{617}-b_{618}$ & $d_{a}\left(\mathrm{NH}_{3}^{+}\right)$ & $\mathrm{NH}_{3}^{+}$antisym. bending \\
\hline 23 & $b_{617}-b_{618}$ & $d_{a}\left(\mathrm{NH}_{3}^{+}\right)$ & $\mathrm{NH}_{3}^{+}$sym. bending \\
\hline 24 & $2 b_{216}-b_{217}-b_{218}$ & $r\left(\mathrm{NH}_{3}^{+}\right)$ & $\mathrm{NH}_{3}^{+}$rocking \\
\hline 25 & $b_{217}-b_{218}$ & $r\left(\mathrm{NH}_{3}^{+}\right)$ & $\mathrm{NH}_{3}^{+}$rocking \\
\hline 26 & $b_{12913}+b_{12911}+b_{13911}-b_{2911}-b_{2912}-b_{2913}$ & $d_{3}\left(\mathrm{CH}_{3}\right)$ & $\mathrm{CH}_{3}$ antisym. bending \\
\hline 27 & $2 b_{12913}-b_{12911}-b_{13911}$ & $d_{a}\left(\mathrm{CH}_{3}\right)$ & $\mathrm{CH}_{3}$ antisym. bending \\
\hline 28 & $b_{12911}-b_{13911}$ & $d_{a}\left(\mathrm{CH}_{3}\right)$ & $\mathrm{CH}_{3}$ sym. bending \\
\hline 29 & $2 b_{2911}-b_{2912}-b_{2913}$ & $r\left(\mathrm{CH}_{3}\right)$ & $\mathrm{CH}_{3}$ rocking \\
\hline 30 & $b_{2912}-b_{2913}$ & $r\left(\mathrm{CH}_{3}\right)$ & $\mathrm{CH}_{3}$ rocking \\
\hline 31 & $\mathrm{~N}_{1}-\mathrm{C}_{2}$ torsion & $t\left(\mathrm{NH}_{3}^{+}\right)$ & $\mathrm{NH}_{3}^{+}$torsion \\
\hline 32 & $\mathrm{C}_{2}-\mathrm{C}_{3}$ torsion & $t\left(\mathrm{CO}_{2}^{-}\right)$ & $\mathrm{CO}_{2}^{-}$torsion \\
\hline 33 & $\mathrm{C}_{2}-\mathrm{C}_{9}$ torsion & $t\left(\mathrm{CO}_{2}^{-}\right)$ & $\mathrm{CH}_{3}$ torsion \\
\hline
\end{tabular}

${ }^{\text {a Arbitrary numbering. }}$

${ }^{\mathrm{b}}$ The atomic numbering is defined in Fig. 1. $r_{i j}$ is the stretching vibration of the bond between atoms $i$ and $j$. $b_{i j k}$ is the in-plane bending vibration of the angle between atoms $i, j$, and $k . f_{i}$ is the out-of-plane bending vibration of the atom $i . t_{i j}$ is the torsion vibration with respect to the bond between atoms $i$ and $j$, which were defined as described in Refs. 47, 48.

to the HF ones. First, vibrational frequencies are undoubtedly nearer to those experimental in the most of cases and, second, the description of the normal modes is clearer. These facts permit an easier comparison with the experimental frequencies and assignments and further refinement processes using a brief number of parameters.

As can be seen in Table V, the HF results overestimate the methylene vibrations by about $300 \mathrm{~cm}^{-1}$ (stretchings) and $150 \mathrm{~cm}^{-1}$ (bendings), while the DFT methodology reduces the deviations to about $150 \mathrm{~cm}^{-1}$ and less than $30 \mathrm{~cm}^{-1}$, respectively. The three bending vibrations involving the $\mathrm{CO}_{2}^{-}$group were predicted at 625,578 , and $498 \mathrm{~cm}^{-1}$ by the B3PW91 calculation, in a good agreement with the experimental frequencies, namely, 671,585 , and $507 \mathrm{~cm}^{-1}$. The HF frequencies are 743,636 , and $517 \mathrm{~cm}^{-1}$, having nonvanished contributions from the methylene rocking mode. In the same way, skeletal $\mathrm{C} 2-\mathrm{C} 3$ and $\mathrm{C} 2-\mathrm{N} 1$ stretching vibrations are also improved in the B3PW91 calculation. Concerning the carboxylate stretching modes, the symmetrical vibration is reported at $1412 \mathrm{~cm}^{-1}$, whereas the antisymmetrical $n_{a}\left(\mathrm{CO}_{2}^{-}\right)$band is hidden behind the strong $d\left(\mathrm{H}_{2} \mathrm{O}\right)$ absorption. The predicted B3PW91 frequencies for these vibrations are 1381 and $1696 \mathrm{~cm}^{-1}$, respectively. The last vibration has been measured at $1596 \mathrm{~cm}^{-1}$ in solid glycine, ${ }^{49}$ and at similar frequencies for other aminoacids. ${ }^{50}$ In solvated glycine we expect a frequency for this vibration not far from the frequency of the solid state and somewhat smaller than the calculated frequency of $1696 \mathrm{~cm}^{-1}$. The source of this behavior is found in the interaction force constant between the two $\mathrm{C}-\mathrm{O}$ stretching coordinates, which is systematically underestimated in quantum-mechanical calculations. This off-diagonal force constant has to be specifically corrected to adjust the theoretical carboxylate stretching frequencies to the experiments.

The ammonium vibrations have to be analyzed separately, because their experimental frequencies are not available. Only the symmetrical bending and one of the rocking vibrations have been observed, although the assignment of the former is not unambiguous. ${ }^{51-54}$ On the other hand, the minimum energy structures obtained by the two methodologies present intramolecular interactions $\mathrm{N} 1-\mathrm{H} 6 \cdots \mathrm{O} 4-\mathrm{C} 3$, which are stronger for the B3PW91 geometry, as was dis- 
TABLE V. 6-31+ $\mathrm{G}^{* *} / \mathrm{SCRF}$ frequencies $\left(\mathrm{cm}^{-1}\right)$, infrared intensities $\left(\mathrm{km} \mathrm{mol}^{-1}\right)$, and normal mode descriptions, obtained for glycine zwitterion. Experimental frequencies have been included for comparison.

\begin{tabular}{|c|c|c|c|c|c|c|c|}
\hline \multicolumn{2}{|c|}{ Experimental $^{\mathrm{a}}$} & \multicolumn{3}{|r|}{ B3PW91 } & \multicolumn{3}{|r|}{$\mathrm{HF}$} \\
\hline Freq. & Assig. & Freq. & IR int. & P.E.D. (greater than $10 \%$ ) & Freq. & IR int. & P.E.D. (greater than $10 \%$ ) \\
\hline & & 3535 & 143.4 & $100 n_{a}\left(\mathrm{NH}_{2}\right)$ & 3738 & 179.8 & $100 n\left(\mathrm{NH}_{3}^{+}\right)$ \\
\hline & & 3454 & 171.8 & $99 n_{s}\left(\mathrm{NH}_{2}\right)$ & 3686 & 255.8 & $99 n\left(\mathrm{NH}_{3}^{+}\right)$ \\
\hline 3016 & $n_{a}\left(\mathrm{CH}_{2}\right)$ & 3199 & 507.4 & $100 n_{a}\left(\mathrm{CH}_{2}\right)$ & 3598 & 104.0 & $99 n\left(\mathrm{NH}_{3}^{+}\right)$ \\
\hline \multirow[t]{4}{*}{2972} & $n_{s}\left(\mathrm{CH}_{2}\right)$ & 3135 & 0.3 & $98 n_{s}\left(\mathrm{CH}_{2}\right)$ & 3354 & 5.2 & $83 n_{a}\left(\mathrm{CH}_{2}\right), 15 n_{s}\left(\mathrm{CH}_{2}\right)$ \\
\hline & & 3072 & 15.1 & $95 n(\mathrm{NH})$ & 3262 & 2.2 & $85 n_{s}\left(\mathrm{CH}_{2}\right), 17 n_{a}\left(\mathrm{CH}_{2}\right)$ \\
\hline & & 1696 & 373.9 & $106 n_{a}\left(\mathrm{CO}_{2}^{-}\right)$ & 1794 & 215.8 & $85 d_{a}\left(\mathrm{NH}_{3}^{+}\right)$ \\
\hline & & 1668 & 49.6 & $97 d_{a}\left(\mathrm{NH}_{3}^{+}\right)$ & 1789 & 812.1 & $77 n_{a}\left(\mathrm{CO}_{2}^{-}\right), 32 d_{a}\left(\mathrm{NH}_{3}^{+}\right)$ \\
\hline 1615 & $d_{a}\left(\mathrm{NH}_{3}^{+}\right)$ & 1636 & 56.0 & $76 d_{a}\left(\mathrm{NH}_{3}^{+}\right), 14 d_{s}\left(\mathrm{NH}_{3}^{+}\right)$ & 1770 & 394.7 & $67 d_{a}\left(\mathrm{NH}_{3}^{+}\right), 29 n_{a}\left(\mathrm{CO}_{2}^{-}\right)$ \\
\hline \multirow[t]{2}{*}{1444} & $d\left(\mathrm{CH}_{2}\right)$ & 1473 & 31.0 & $91 d\left(\mathrm{CH}_{2}\right)$ & 1641 & 405.5 & $94 d_{s}\left(\mathrm{NH}_{3}^{+}\right)$ \\
\hline & & 1440 & 478.5 & $79 d_{s}\left(\mathrm{NH}_{3}^{+}\right), 10 n\left(\mathrm{CO}_{2}^{-}\right)$ & 1604 & 1.6 & $93 d\left(\mathrm{CH}_{2}\right)$ \\
\hline 1412 & $n_{s}\left(\mathrm{CO}_{2}^{-}\right)$ & 1381 & 314.9 & $62 n_{s}\left(\mathrm{CO}_{2}^{-}\right), 24 n(\mathrm{CC}), 15 d\left(\mathrm{CO}_{2}^{-}\right)$ & 1561 & 281.2 & $41 n_{s}\left(\mathrm{CO}_{2}^{-}\right), 25 n(\mathrm{CO}), 24 w\left(\mathrm{CH}_{2}\right)$ \\
\hline 1330 & $w\left(\mathrm{CH}_{2}\right)$ & 1330 & 27.7 & $76 w\left(\mathrm{CH}_{2}\right)$ & 1476 & 169.0 & $55 w\left(\mathrm{CH}_{2}\right), 25 n_{s}\left(\mathrm{CO}_{2}^{-}\right)$ \\
\hline 1320 & $t\left(\mathrm{CH}_{2}\right)$ & 1311 & 11.1 & $62 t\left(\mathrm{CH}_{2}\right), 18 r\left(\mathrm{NH}_{3}^{+}\right)$ & 1437 & 22.6 & $58 t\left(\mathrm{CH}_{2}\right), 14 r\left(\mathrm{NH}_{3}^{+}\right)$ \\
\hline \multirow[t]{2}{*}{1121} & $r\left(\mathrm{NH}_{3}^{+}\right)$ & 1104 & 133.7 & $69 r\left(\mathrm{NH}_{3}^{+}\right), 12 w\left(\mathrm{CH}_{2}\right)$ & 1202 & 4.3 & $38 r\left(\mathrm{NH}_{3}^{+}\right), 28 t\left(\mathrm{CH}_{2}\right), 22 r\left(\mathrm{CH}_{2}\right)$ \\
\hline & & 1102 & 1.5 & $49 r\left(\mathrm{NH}_{3}^{+}\right), 16 r\left(\mathrm{CH}_{2}\right)$ & 1179 & 60.8 & $61 r\left(\mathrm{NH}_{3}^{+}\right), 31 w\left(\mathrm{CH}_{2}\right)$ \\
\hline \multirow[t]{2}{*}{1031} & $n(\mathrm{CN})$ & 1002 & 16.6 & $90 n(\mathrm{CN})$ & 1064 & 10.8 & $72 n(\mathrm{CN})$ \\
\hline & & 934 & 28.2 & $49 r\left(\mathrm{CH}_{2}\right), 29 r\left(\mathrm{NH}_{3}^{+}\right), 22 g\left(\mathrm{OCO}^{-}\right)$ & 989 & 41.1 & $42 r\left(\mathrm{NH}_{3}^{+}\right), 31 r\left(\mathrm{CH}_{2}\right), 20 g\left(\mathrm{OCO}^{-}\right)$ \\
\hline 897 & $n(\mathrm{CC})$ & 869 & 111.6 & $52 n(\mathrm{CC}), 34 d\left(\mathrm{CO}_{2}^{-}\right)$ & 938 & 104.8 & $34 n(\mathrm{CC}), 32 d\left(\mathrm{CO}_{2}^{-}\right), 13 n(\mathrm{CN})$ \\
\hline 671 & $d\left(\mathrm{CO}_{2}^{-}\right)$ & 675 & 9.9 & $41 d\left(\mathrm{CO}_{2}^{-}\right), 13 W\left(\mathrm{CO}_{2}^{-}\right), 13 n(\mathrm{CC})$ & 743 & 14.6 & $28 d\left(\mathrm{CO}_{2}^{-}\right), 20 g\left(\mathrm{OCO}^{-}\right), 13 r\left(\mathrm{CH}_{2}\right)$ \\
\hline 585 & $W\left(\mathrm{CO}_{2}^{-}\right)$ & 578 & 2.3 & $76 g\left(\mathrm{OCO}^{-}\right)$ & 636 & 25.3 & $44 g\left(\mathrm{OCO}^{-}\right), 28 r\left(\mathrm{CH}_{2}\right), 19 d\left(\mathrm{CO}_{2}^{-}\right)$ \\
\hline \multirow[t]{4}{*}{507} & $g\left(\mathrm{CO}_{2}^{-}\right)$ & 498 & 69.8 & $40 w\left(\mathrm{CO}_{2}^{-}\right), 18 n(\mathrm{CC}), 16 d\left(\mathrm{CO}_{2}^{-}\right)$ & 517 & 40.9 & $47 w\left(\mathrm{CO}_{2}^{-}\right)$ \\
\hline & & 316 & 0.0 & $108 t\left(\mathrm{NH}_{3}^{+}\right)$ & 290 & 53.7 & $65 d(\mathrm{CCN})$ \\
\hline & & 271 & 118.5 & $78 d(\mathrm{CCN}), 52 d\left(\mathrm{CO}_{2}^{-}\right)$ & 203 & 6.5 & $94 t\left(\mathrm{NH}_{3}^{+}\right)$ \\
\hline & & 53 & 0.6 & $50 t\left(\mathrm{NH}_{3}^{+}\right), 47 t\left(\mathrm{CO}_{2}^{-}\right)$ & 86 & 0.9 & $67 t\left(\mathrm{CO}_{2}^{-}\right), 35 t\left(\mathrm{NH}_{3}^{+}\right)$ \\
\hline
\end{tabular}

${ }^{a}$ Experimental frequencies and assignments are taken from Ref. 51, except the frequency of $1615 \mathrm{~cm}^{-1}$ (Ref. 53).

cussed previously. This fact gives rise to a $n(\mathrm{NH})$ frequency, $3072 \mathrm{~cm}^{-1}$, significantly lower than the rest, 3535 and $3454 \mathrm{~cm}^{-1}$. Comparing these calculated values with the experimental ones for solid glycine, 3058 and $3152 \mathrm{~cm}^{-1}$, we can expect a similar environment for the $\mathrm{N}-\mathrm{H}$ bond involved in these vibrations. It is clear that the intermolecular hydrogen bond of solid glycine has been substituted by the intramolecular interaction previously mentioned. This result is not so enhanced in the HF results because the $\mathrm{H} \cdots \mathrm{O}$ distance is longer, $2.150 \AA$, than that of the B3PW91 structure, 1.813 $\AA$. The question here is what happens in solution with a glycine molecule. The answer will not be apparent while the $\mathrm{NH}_{3}^{+}$vibrations have not been undoubtedly assigned; nevertheless, the two bending vibrations experimentally reported up to now, $d_{a}\left(\mathrm{NH}_{3}^{+}\right)$and $r\left(\mathrm{NH}_{3}^{+}\right)$, indicate that interactions stronger than those directly produced by a continuum solvent would be present. They should also affect to the carboxylate moiety, but we would expect the spectral influences to be lower.

The qualitative features of the calculated infrared spectra can be seen in Fig. 2, displayed from data listed in the Table $\mathrm{V}$. Apart from the drastic difference originated by the lowfrequency $n(\mathrm{NH})$ vibration, the calculated B3PW91 intensities are lower than those obtained by HF methodology for the ammonium vibrations, higher for the carboxylate and skeletal vibrations and similar for the methylene vibrational modes. If we take into account only the normal mode descriptions these differences are not satisfactorily explained. Therefore they have to be found by comparing the atomic charges obtained in both methods. The Mulliken charge dis- tribution of the $\mathrm{HF}$ calculation gives $+0.324,+0.601$, -0.806 , and -0.731 to atoms $\mathrm{C} 2, \mathrm{C} 3, \mathrm{O} 4$, and $\mathrm{O} 5$, respectively, while the corresponding charges are $+0.237,+0.367$, -0.648 , and -0.625 in the case of the B3PW91 calculation. The enhancement of the net charges in the heavy atoms (except $\mathrm{N}$ ) is fully compatible with the calculated intensities. Experimental infrared intensities are not available because only Raman spectra of glycine solutions are reported.

The most of topics set out above for the vibrational dynamics of glycine can be applied to the alanine molecule, whose results are summarized in the Table VI. As can be observed, the agreement between the observed and the B3PW91 frequencies is satisfactory; in addition, the normal mode descriptions from the P.E.D., support the proposed assignments on the basis of experiments. ${ }^{55}$ Taking into account that these assignments were based in selective deuterium exchanges in all the hydrogen atoms, the reached agreement confirms the availability of the hybrid functional B3PW91 in reproducing vibrational spectra of highly polar species in solution.

Compared with the B3PW91 results for glycine, a significant difference can be observed involving the ammonium moiety. As mentioned previously, an internal five-membered cycle stabilizes the structure of a glycine molecule, while in alanine the three hydrogen atoms from the ammonium group have more similar environments, as obtained from the B3PW91 structural optimization. This implies that the related stretching vibrations, $n(\mathrm{NH})$ will be strongly coupled, so that they will appear at different frequencies depending on their symmetries: a symmetrical and two antisymmetrical vi- 
TABLE VI. 6-31+ $\mathrm{G}^{* *} / \mathrm{SCRF}$ frequencies ${ }^{\mathrm{a}}\left(\mathrm{cm}^{-1}\right)$, infrared intensities $\left(\mathrm{km} \mathrm{mol}^{-1}\right)$, and normal mode descriptions, obtained for alanine zwitterion. Experimental frequencies have been included for comparison.

\begin{tabular}{|c|c|c|c|c|c|c|c|}
\hline \multicolumn{2}{|r|}{ Experimental $^{\mathrm{a}}$} & \multicolumn{3}{|r|}{ B3PW91 } & \multicolumn{3}{|r|}{$\mathrm{HF}$} \\
\hline Freq. & Assig. & Freq. & IR int. & P.E.D. (greater than $10 \%$ ) & Freq. & IR int. & P.E.D. (greater than $10 \%$ ) \\
\hline & & 3545 & 99.7 & $98 n\left(\mathrm{NH}_{3}^{+}\right)$ & 3756 & 187.4 & $97 n\left(\mathrm{NH}_{3}^{+}\right)$ \\
\hline & & 3436 & 300.8 & $100 n\left(\mathrm{NH}_{3}^{+}\right)$ & 3705 & 188.6 & $101 n\left(\mathrm{NH}_{3}^{+}\right)$ \\
\hline & & 3333 & 185.2 & $101 n\left(\mathrm{NH}_{3}^{+}\right)$ & 3614 & 126.2 & $102 n\left(\mathrm{NH}_{3}^{+}\right)$ \\
\hline & & 3183 & 8.3 & $92 n(\mathrm{CH})$ & 3342 & 8.3 & $97 n(\mathrm{CH})$ \\
\hline 3003 & $n_{a}\left(\mathrm{CH}_{3}\right)$ & 3154 & 2.1 & $94 n_{a}\left(\mathrm{CH}_{3}\right)$ & 3280 & 6.3 & $98 n_{a}\left(\mathrm{CH}_{3}\right)$ \\
\hline 2993 & $n_{a}\left(\mathrm{CH}_{3}\right)$ & 3134 & 13.9 & $97 n_{a}\left(\mathrm{CH}_{3}\right)$ & 3262 & 25.8 & $97 n_{a}\left(\mathrm{CH}_{3}\right)$ \\
\hline \multirow[t]{2}{*}{2949} & $n_{s}\left(\mathrm{CH}_{3}\right)$ & 3059 & 18.4 & $97 n_{s}\left(\mathrm{CH}_{3}\right)$ & 3195 & 23.2 & $97 n_{s}\left(\mathrm{CH}_{3}\right)$ \\
\hline & & 1661 & 541.7 & $56 d_{a}\left(\mathrm{NH}_{3}^{+}\right), 49 n\left(\mathrm{CO}_{2}^{-}\right)$ & 1783 & 117.8 & $94 d_{a}\left(\mathrm{NH}_{3}^{+}\right)$ \\
\hline \multirow[t]{2}{*}{1607} & $n\left(\mathrm{CO}_{2}^{-}\right)+d_{a}\left(\mathrm{NH}_{3}^{+}\right)$ & 1653 & 586.5 & $58 d_{a}\left(\mathrm{NH}_{3}^{+}\right), 45 n\left(\mathrm{CO}_{2}^{-}\right)$ & 1768 & 47.2 & $95 d_{a}\left(\mathrm{NH}_{3}^{+}\right)$ \\
\hline & & 1636 & 319.0 & $71 d_{a}\left(\mathrm{NH}_{3}^{+}\right), 24 n\left(\mathrm{CO}_{2}^{-}\right)$ & 1756 & 1624.3 & $120 n\left(\mathrm{CO}_{2}^{-}\right)$ \\
\hline 1480 & $d_{a}\left(\mathrm{CH}_{3}\right)$ & 1488 & 72.1 & $77 d_{a}\left(\mathrm{CH}_{3}\right)$ & 1652 & 362.4 & $99 d_{a}\left(\mathrm{NH}_{3}^{+}\right)$ \\
\hline \multirow[t]{2}{*}{1459} & $d_{a}\left(\mathrm{CH}_{3}\right)$ & 1482 & 46.4 & $79 d_{a}\left(\mathrm{CH}_{3}\right)$ & 1613 & 86.2 & $74 d_{a}\left(\mathrm{CH}_{3}\right)$ \\
\hline & & 1478 & 349.9 & $73 d_{s}\left(\mathrm{NH}_{3}^{+}\right)$ & 1603 & 0.7 & $92 d_{a}\left(\mathrm{CH}_{3}\right)$ \\
\hline 1410 & $n\left(\mathrm{CO}_{2}^{-}\right)$ & 1415 & 123.1 & $55 d_{s}\left(\mathrm{CH}_{3}\right), 22 n\left(\mathrm{CO}_{2}^{-}\right)$ & 1564 & 199.6 & $36 n\left(\mathrm{CO}_{2}^{-}\right), 21 d_{a}\left(\mathrm{CH}_{3}\right), 16 n(\mathrm{CC})$ \\
\hline 1375 & $d_{s}\left(\mathrm{CH}_{3}\right)$ & 1392 & 69.0 & $46 d_{s}\left(\mathrm{CH}_{3}\right), 28 n\left(\mathrm{CO}_{2}^{-}\right)$ & 1536 & 42.4 & $83 d_{s}\left(\mathrm{CH}_{3}\right)$ \\
\hline 1351 & $d(\mathrm{CH})$ & 1378 & 104.4 & $67 d(\mathrm{CH}), 17 n\left(\mathrm{CO}_{2}^{-}\right)$ & 1511 & 73.4 & $76 d(\mathrm{CH})$ \\
\hline 1301 & $d(\mathrm{CH})$ & 1313 & 42.0 & $61 d(\mathrm{CH})$ & 1447 & 106.6 & $60 d(\mathrm{CH})$ \\
\hline 1220 & $r\left(\mathrm{NH}_{3}^{+}\right)$ & 1194 & 11.5 & $28 r\left(\mathrm{NH}_{3}^{+}\right), 24 r\left(\mathrm{CH}_{3}\right), 13 d(\mathrm{CCN})$ & 1293 & 19.12 & $8 r\left(\mathrm{CH}_{3}\right), 25 r\left(\mathrm{NH}_{3}^{+}\right), 17 d(\mathrm{CCN})$ \\
\hline 1145 & $r\left(\mathrm{NH}_{3}^{+}\right)$ & 1108 & 46.1 & $35 r\left(\mathrm{NH}_{3}^{+}\right), 27 d(\mathrm{CH})$ & 1202 & 41.2 & $22 r\left(\mathrm{NH}_{3}^{+}\right), 21 r\left(\mathrm{CH}_{3}\right)$ \\
\hline 1110 & $n(\mathrm{CN})$ & 1087 & 13.5 & $38 r\left(\mathrm{CH}_{3}\right), 22 n(\mathrm{CN}), 18 n(\mathrm{CC})$ & 1177 & 15.0 & $24 r\left(\mathrm{CH}_{3}\right), 21 n(\mathrm{CN}), 18 n(\mathrm{CC})$ \\
\hline 995 & $r\left(\mathrm{CH}_{3}\right)$ & 972 & 38.1 & $37 r\left(\mathrm{NH}_{3}^{+}\right), 31 r\left(\mathrm{CH}_{3}\right)$ & 1039 & 20.0 & $36 r\left(\mathrm{NH}_{3}^{+}\right), 33 r\left(\mathrm{CH}_{3}\right), 14 n(\mathrm{CN})$ \\
\hline 1001 & $n(\mathrm{CC})$ & 953 & 16.9 & $56 r\left(\mathrm{NH}_{3}^{+}\right), 22 n(\mathrm{CC}), 19 r\left(\mathrm{CH}_{3}\right)$ & 1014 & 24.9 & $52 r\left(\mathrm{NH}_{3}^{+}\right), 26 n(\mathrm{CC}), 15 r\left(\mathrm{CH}_{3}\right)$ \\
\hline 922 & $r\left(\mathrm{CH}_{3}\right)$ & 885 & 45.8 & $34 n(\mathrm{CC}), 31 n(\mathrm{CN}), 23 r\left(\mathrm{CH}_{3}\right)$ & 968 & 40.4 & $35 n(\mathrm{CC}), 22 r\left(\mathrm{CH}_{3}\right), 19 n(\mathrm{CN})$ \\
\hline 850 & $n(\mathrm{CC})$ & 820 & 47.9 & $33 d\left(\mathrm{CO}_{2}^{-}\right), 26 n(\mathrm{CC}), 21 n(\mathrm{CN})$ & 878 & 43.6 & $34 n(\mathrm{CN}), 24 d\left(\mathrm{CO}_{2}^{-}\right)$ \\
\hline 775 & $g\left(\mathrm{OCO}^{-}\right)$ & 773 & 9.0 & $70 g\left(\mathrm{OCO}^{-}\right)$ & 863 & 22.5 & $62 g\left(\mathrm{OCO}^{-}\right)$ \\
\hline 640 & $d\left(\mathrm{CO}_{2}^{-}\right)$ & 654 & 1.7 & $34 d(\mathrm{CCN}), 28 d\left(\mathrm{CO}_{2}^{-}\right), 14 w\left(\mathrm{CO}_{2}^{-}\right)$ & 708 & 9.6 & $31 d(\mathrm{CCN}), 28 d\left(\mathrm{CO}_{2}^{-}\right), 13 w\left(\mathrm{CO}_{2}\right)$ \\
\hline 527 & $w\left(\mathrm{CO}_{2}^{-}\right)$ & 509 & 48.8 & $29 w\left(\mathrm{CO}_{2}^{-}\right), 21 d(\mathrm{CCN}), 14 d\left(\mathrm{CO}_{2}^{-}\right)$ & 550 & 44.1 & $28 w\left(\mathrm{CO}_{2}^{-}\right), 19 d(\mathrm{CCN}), 11 d\left(\mathrm{CO}_{2}^{-}\right)$ \\
\hline 399 & $d(\mathrm{CCN})$ & 349 & 12.6 & $79 d(\mathrm{CCN})$ & 368 & 11.5 & $81 d(\mathrm{CCN})$ \\
\hline 283 & $d(\mathrm{CCN})$ & 277 & 52.8 & $89 d(\mathrm{CCN}), 25 w\left(\mathrm{CO}_{2}^{-}\right)$ & 298 & 32.8 & $75 d(\mathrm{CCN}), 25 w\left(\mathrm{CO}_{2}^{-}\right)$ \\
\hline \multirow[t]{4}{*}{219} & $d(\mathrm{CCN})$ & 260 & 26.1 & $57 d(\mathrm{CCN})$ & 274 & 34.8 & $67 d(\mathrm{CCN}), 17 g\left(\mathrm{OCO}^{-}\right)$ \\
\hline & & 235 & 1.4 & $71 t\left(\mathrm{CH}_{3}\right), 25 t\left(\mathrm{NH}_{3}^{+}\right)$ & 243 & 8.5 & $81 t\left(\mathrm{CH}_{3}\right)$ \\
\hline & & 222 & 17.7 & $64 t\left(\mathrm{NH}_{3}^{+}\right), 22 d(\mathrm{CCN}), 12 t\left(\mathrm{CH}_{3}\right)$ & 191 & 3.5 & $102 t\left(\mathrm{NH}_{3}^{+}\right)$ \\
\hline & & 60 & 8.5 & $76 t\left(\mathrm{CO}_{2}^{-}\right), 24 t\left(\mathrm{NH}_{3}^{+}\right)$ & 80 & 4.2 & $89 t\left(\mathrm{CO}_{2}^{-}\right), 12 t\left(\mathrm{NH}_{3}^{+}\right)$ \\
\hline
\end{tabular}

${ }^{\mathrm{a}}$ Experimental frequencies and assignments are taken from Ref. 55.

brations. Because these bands can not be observed in solution, we have to obtain information from the $d\left(\mathrm{NH}_{3}^{+}\right)$bending modes. One of these has been reported at $1607 \mathrm{~cm}^{-1}$ as having a mixed character of $d_{a}\left(\mathrm{NH}_{3}^{+}\right)$and $n\left(\mathrm{CO}_{2}^{-}\right) \cdot{ }^{56}$ To correlate it with the theoretical spectra we can choose among three frequencies in Table VI, namely, 1661, 1653, and $1636 \mathrm{~cm}^{-1}$. At the light of the potential energy distribution, the aforementioned modes are involved in the three frequencies with nonnegligible contributions, in agreement with the previous assignment. For glycine molecule, the calculated B3PW91 values for the two $d_{a}\left(\mathrm{NH}_{3}^{+}\right)$vibrations were 1668 and $1636 \mathrm{~cm}^{-1}$, close to those obtained for alanine. However, the symmetrical $d_{s}\left(\mathrm{NH}_{3}^{+}\right)$vibration is calculated with a difference of $+48 \mathrm{~cm}^{-1}$, as a consequence of the intramolecular interaction, that upshifts the stretching vibrations while the corresponding bending vibrations are downshifted. ${ }^{57}$

The experimental frequencies measured between 1500 and $1200 \mathrm{~cm}^{-1}$ for alanine solution have been calculated with differences ranging from 5 to $23 \mathrm{~cm}^{-1}$ when the DFT methodology was used. Normal mode descriptions are consistent with the reported assignments in all the cases. Results from the HF calculation overestimates the frequencies in this region by more than $100 \mathrm{~cm}^{-1}$; although the normal mode descriptions can be well correlated with the B3PW91 results and the experimental assignments. Comparisons for frequencies smaller than $1000 \mathrm{~cm}^{-1}$ show the same trends as those previously discussed for glycine. We would like to emphasize that the agreement of DFT-observed frequencies for the three $\mathrm{CO}_{2}^{-}$bending vibrations are as satisfactory as in glycine, thus supporting the validity of this methodology.

We have displayed the calculated infrared spectrum of solvated alanine in Fig. 3. There we can observe a very intense band in the $\mathrm{HF}$ spectrum that corresponds to a $\mathrm{CO}_{2}^{-}$ stretching vibration. Its intensity, $1621.3 \mathrm{~km} \mathrm{~mol}^{-1}$, is twice that of the related vibration for glycine (see Table V), the calculated charge distribution being very similar for the two molecules. As regards the P.E.D. of the corresponding frequencies, we can see that for glycine the $n\left(\mathrm{CO}_{2}^{-}\right)$coordinates are distributed into two close frequencies, namely, 1787 and $1770 \mathrm{~cm}^{-1}$, while for alanine the same coordinate describes a single frequency, $1756 \mathrm{~cm}^{-1}$. The contribution of $120 \%$ indicates high off-diagonal negative terms in the P.E.D.

The calculated diagonal force constants are listed in the 
TABLE VII. Diagonal force constants (in mdyn/Å) calculated for glycine and alanine.

\begin{tabular}{|c|c|c|c|c|c|c|c|}
\hline \multicolumn{4}{|c|}{ Glycine } & \multicolumn{4}{|c|}{ Alanine } \\
\hline Coord. $^{\text {a }}$ & Symbol & $\mathrm{HF}$ & B3PW91 & Coord. ${ }^{a}$ & Symbol & $\mathrm{HF}$ & B3PW91 \\
\hline 1 & $n(\mathrm{CN})$ & 4.897 & 4.594 & 1 & $n(\mathrm{CN})$ & 4.516 & 4.098 \\
\hline 2 & $n(\mathrm{CC})$ & 4.553 & 3.961 & 2 & $n(\mathrm{CC})$ & 4.380 & 3.668 \\
\hline 3 & $n\left(\mathrm{CO}_{2}^{-}\right)$ & 11.267 & 9.349 & 3 & $n(\mathrm{CC})$ & 4.668 & 4.288 \\
\hline 4 & $n\left(\mathrm{CO}_{2}^{-}\right)$ & 12.090 & 10.778 & 4 & $n\left(\mathrm{CO}_{2}^{-}\right)$ & 11.249 & 9.512 \\
\hline 5 & $n_{s}\left(\mathrm{CH}_{2}\right)$ & 6.050 & 5.534 & 5 & $n\left(\mathrm{CO}_{2}^{-}\right)$ & 11.784 & 10.336 \\
\hline 6 & $n_{a}\left(\mathrm{CH}_{2}\right)$ & 5.973 & 5.482 & 6 & $n(\mathrm{CH})$ & 6.118 & 5.551 \\
\hline 7 & $n(\mathrm{NH})$ & 7.484 & 5.193 & 7 & $n(\mathrm{NH})$ & 7.628 & 6.239 \\
\hline 8 & $n(\mathrm{NH})$ & 7.334 & 6.773 & 8 & $n(\mathrm{NH})$ & 7.726 & 6.941 \\
\hline 9 & $n(\mathrm{NH})$ & 7.666 & 6.773 & 9 & $n(\mathrm{NH})$ & 7.344 & 6.512 \\
\hline 10 & $d\left(\mathrm{CO}_{2}^{-}\right)$ & 1.496 & 1.342 & 10 & $n_{s}\left(\mathrm{CH}_{3}\right)$ & 5.905 & 5.412 \\
\hline 11 & $w\left(\mathrm{CO}_{2}^{-}\right)$ & 1.277 & 1.275 & 11 & $n_{a}\left(\mathrm{CH}_{3}\right)$ & 5.784 & 5.358 \\
\hline 12 & $g\left(\mathrm{OCO}^{-}\right)$ & 0.597 & 0.491 & 12 & $n_{a}\left(\mathrm{CH}_{3}\right)$ & 5.744 & 5.298 \\
\hline 13 & $d\left(\mathrm{CH}_{2}\right)$ & 0.932 & 0.815 & 13 & $d\left(\mathrm{CO}_{2}^{-}\right)$ & 1.476 & 1.273 \\
\hline 14 & $d(\mathrm{CCN})$ & 1.812 & 2.046 & 14 & $w\left(\mathrm{CO}_{2}^{-}\right)$ & 1.228 & 1.116 \\
\hline 15 & $r\left(\mathrm{CH}_{2}\right)$ & 0.887 & 0.742 & 15 & $g\left(\mathrm{OCO}^{-}\right)$ & 0.614 & 0.502 \\
\hline 16 & $w\left(\mathrm{CH}_{2}\right)$ & 0.829 & 0.710 & 16 & $d(\mathrm{CH})$ & 0.784 & 0.664 \\
\hline 17 & $t\left(\mathrm{CH}_{2}\right)$ & 0.792 & 0.705 & 17 & $d(\mathrm{CH})$ & 0.890 & 0.767 \\
\hline 18 & $d_{s}\left(\mathrm{NH}_{3}^{+}\right)$ & 0.678 & 0.607 & 18 & $d(\mathrm{CCN})$ & 2.173 & 2.109 \\
\hline 19 & $d_{a}\left(\mathrm{NH}_{3}^{+}\right)$ & 0.718 & 0.597 & 19 & $d(\mathrm{CCN})$ & 1.751 & 1.523 \\
\hline 20 & $d_{a}\left(\mathrm{NH}_{3}^{+}\right)$ & 0.719 & 0.662 & 20 & $d(\mathrm{CCN})$ & 2.081 & 1.824 \\
\hline 21 & $r\left(\mathrm{NH}_{3}^{+}\right)$ & 0.744 & 0.760 & 21 & $d_{s}\left(\mathrm{NH}_{3}^{+}\right)$ & 0.660 & 0.578 \\
\hline 22 & $r\left(\mathrm{NH}_{3}^{+}\right)$ & 0.754 & 0.672 & 22 & $d_{a}\left(\mathrm{NH}_{3}^{+}\right)$ & 0.726 & 0.627 \\
\hline 23 & $t\left(\mathrm{NH}_{3}^{+}\right)$ & 0.072 & 0.190 & 23 & $d_{a}\left(\mathrm{NH}_{3}^{+}\right)$ & 0.728 & 0.647 \\
\hline \multirow[t]{10}{*}{24} & $t\left(\mathrm{CO}_{2}^{-}\right)$ & 0.111 & 0.191 & 24 & $r\left(\mathrm{NH}_{3}^{+}\right)$ & 0.698 & 0.636 \\
\hline & & & & 25 & $r\left(\mathrm{NH}_{3}^{+}\right)$ & 0.684 & 0.606 \\
\hline & & & & 26 & $d_{s}\left(\mathrm{CH}_{3}\right)$ & 0.673 & 0.572 \\
\hline & & & & 27 & $d_{a}\left(\mathrm{CH}_{3}\right)$ & 0.667 & 0.579 \\
\hline & & & & 28 & $d_{a}\left(\mathrm{CH}_{3}\right)$ & 0.657 & 0.570 \\
\hline & & & & 29 & $r\left(\mathrm{CH}_{3}\right)$ & 0.751 & 0.642 \\
\hline & & & & 30 & $r\left(\mathrm{CH}_{3}\right)$ & 0.771 & 0.663 \\
\hline & & & & 31 & $t\left(\mathrm{NH}_{3}^{+}\right)$ & 0.064 & 0.100 \\
\hline & & & & 32 & $t\left(\mathrm{CO}_{2}^{-}\right)$ & 0.131 & 0.080 \\
\hline & & & & 33 & $t\left(\mathrm{CH}_{3}\right)$ & 0.115 & 0.003 \\
\hline
\end{tabular}

${ }^{\mathrm{a}}$ See Tables III and IV for coordinate descriptions.

Table VII. Off-diagonal terms are available from the authors on request. The general trend for both the DFT force constants are smaller than those calculated from HF methodology. There are few exceptions to this result; as a consequence of the $\mathrm{N} 1-\mathrm{H} 6 \cdots \mathrm{O} 4-\mathrm{C} 3$ interaction, the $t\left(\mathrm{NH}_{3}^{+}\right)$ torsional force constant is higher in DFT than in HF calculation. For glycine, it goes from 0.072 (HF) to 0.190 (DFT)

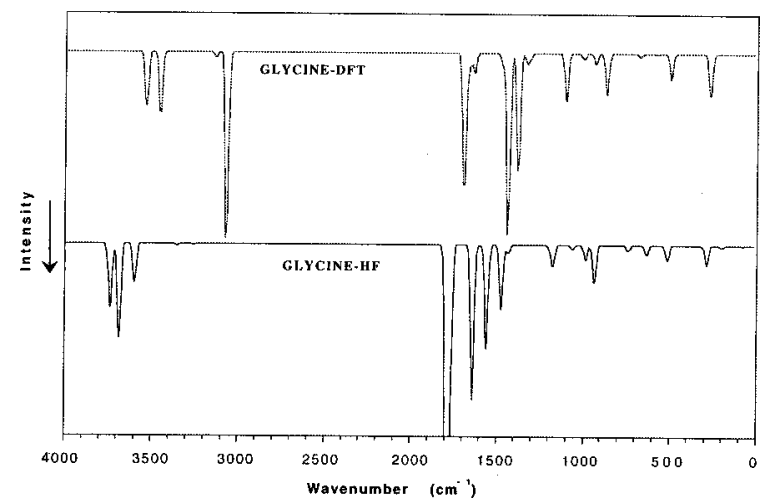

FIG. 2. HF/6-31+G** (HF) and B3PW91/6-31+G** (DFT) infrared spectra of glycine zwitterion in solution.
mdyn/Å, while for alanine the values are 0.064 and 0.106 mdyn/ $/$, respectively. A significant increase is also obtained for the carboxylate torsional mode, which is more enhanced in glycine, while the $t\left(\mathrm{CH}_{3}\right)$ torsional force constant of alanine follows the general trend. A higher decrease occurs for coordinate number 7 of glycine, $n(\mathrm{NH})$, which goes from 7.484 (HF) to $5.183 \mathrm{mdyn} / \AA \mathrm{A}$ (DFTAt), the light of the vibra-

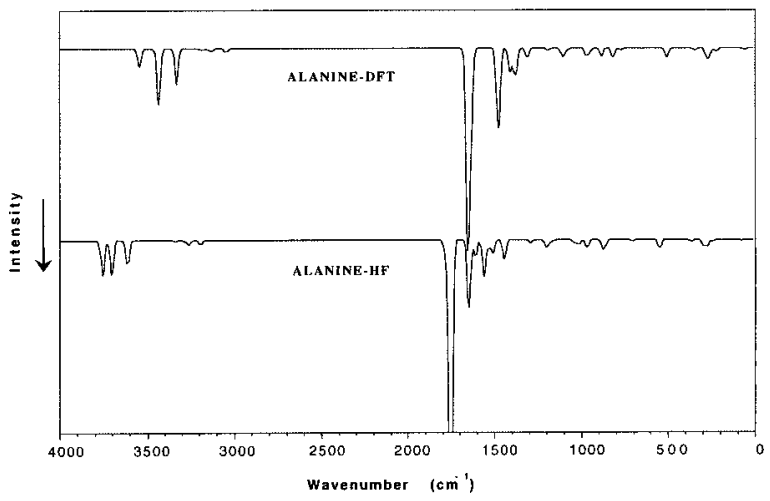

FIG. 3. HF/6-31+G** (HF) and B3PW91/6-31+G** (DFT) infrared spectra of alanine zwitterion in solution. 
tional frequency comparison, previously discussed. We can postulate that a fitted value for a solvated ammonium $\mathrm{N}-\mathrm{H}$ stretching force constant would be between the two values calculated for glycine by the DFT methodology, 5.193 and $6.703 \mathrm{mdyn} / \AA$, which correspond to an hydrogen-bonded and a free $\mathrm{N}-\mathrm{H}$ bond, respectively. The $n\left(\mathrm{CO}_{2}^{-}\right)$force constants also decrease appreciably for glycine and alanine on going from HF to DFT, while force constants for skeletal and nonpolar moieties are more similar.

\section{CONCLUSIONS}

In this paper we have performed a thorough analysis of the performance of a hybrid-three parameters density functional (B3PW91) together with a continuum model to study different aspects of the aminoacid zwitterion chemistry in solution. Geometries, energies, and vibrational spectra of glycine and alanine aminoacid zwitterions have been studied at the B3PW91/6-31+G** level and the results compared with those obtained at the HF and MP2/6-31+G** levels. Solvents effects have been incorporated by means of an ellipsoidal cavity model with a multipolar expansion (up to sixth order) of the solute's electrostatic potential from which the analytical first and second derivatives can be readily obtained.

The geometrical parameters obtained at the B3PW91 and MP2 levels are very similar both for alanine and glycine. The main difference is found in the zwitterionic form of the glycine aminoacid. In this case MP2 calculations predict a $\mathrm{C}_{1}$ structure while at the B3PW91 level a symmetric $\mathrm{C}_{s}$ structure is predicted as the absolute minimum. This discrepancy is due to very subtle energy differences. So, at the MP2 level the $\mathrm{C}_{1}$ structure is only $0.04 \mathrm{kcal} / \mathrm{mol}$ more stable than the $\mathrm{C}_{s}$ one.

The energy values obtained at the B3PW91 level are also very close to the MP2 ones. HF calculations are shown to produce energy barriers for the neutral to zwitterion intramolecular conversion up to five times larger than when correlation energy is considered. A large part of the divergence with respect to experimental estimations of the glycine zwitterion stability seems to arise not from deficiencies of the density functional methodology but mainly to limitations of the selected cavity model. Results can be improved using a molecular-shaped cavity and fitting the atomic radii to the strength of the solute-solvent interactions. Further differences could be accounted for taking into account other unconsidered energy contributions.

The results from the vibrational analysis of glycine and alanine, and the comparison with the experimental spectra, demonstrate that the use of the B3PW91 density functional gives rise to a meaningful amelioration of the vibrational frequencies and normal mode descriptions of aminoacids in solution. We have also confirmed that specific intra- and/or inter-molecular interactions by hydrogen bonds play a nonvanished role in reproducing the vibrational behavior of these molecules.

We believe that the study here presented supports the validity of nonlocal density functionals, and in particular hybrid functionals, for obtaining good descriptions of aminoac- ids chemistry in solution. Because of the lower computational cost of these calculations, density functional techniques are an interesting alternative to ab initio correlated methods for the theoretical study of bioorganic compounds such as aminoacids and polipeptids.

\section{ACKNOWLEDGMENTS}

This work has been partly supported by DGICYT Project PB96-0792. I.T. acknowledges a post-doctoral contract of the Ministerio de Educación and the Universidad de Valencia.

${ }^{1}$ (a) J. Tomasi and M. Persico, Chem. Rev. 94, 2027 (1994); (b) C. J. Cramer and D. G. Truhlar, in Reviews in Computational Chemistry, edited by K. B. Lipkowitz and D. B. Boyd (VCH, New York, 1994); (c) J. L. Rivail and D. Dinaldi, in Computational Chemistry. Reviews of Current Trends, Vol. 1, edited by J. Leszczynski (World Scientific, Singapore, 1996).

${ }^{2}$ C. Reichardt, in Solvents and Solvent Effects in Organic Chemistry (VCH, New York, 1988).

${ }^{3}$ G. Albrecht and R. B. Corey, J. Am. Chem. Soc. 61, 1087 (1939).

${ }^{4}$ P. G. Jonsson and A. Kvick, Acta Crystallogr., Sect. B: Struct. Crystallogr. Cryst. Chem. 28, 1827 (1972).

${ }^{5}$ Y. Ding and K. Krogh-Jespersen, Chem. Phys. Lett. 199, 261 (1992).

${ }^{6}$ M. W. Wong, K. B. Wiberg, and M. J. Frisch, J. Am. Chem. Soc. 114, 523 (1992).

${ }^{7}$ (a) S. Romano and E. Clementi, Int. J. Quantum Chem. 14, 839 (1978); (b) G. Alagona, C. Ghio, and P. A. Kollman, J. Mol. Struct.: THEOCHEM 166, 385 (1988); (c) G. Alagona and C. Ghio, J. Mol. Model. 47, 139 (1990).

${ }^{8}$ R. Bonaccorsi, P. Palla, and J. Tomasi, J. Am. Chem. Soc. 106, 1945 (1984).

${ }^{9}$ F. R. Tortonda, J. L. Pascual-Ahuir, E. Silla, and I. Tuñón, Chem. Phys. Lett. 260, 21 (1996)

${ }^{10}$ J. Andzelm, C. Kölmeland, and A. Klamt, J. Chem. Phys. 21, 9312 (1995).

${ }^{11}$ Y. Ding and K. Krogh-Jespersen, J. Comput. Chem. 17, 338 (1996).

${ }^{12}$ J. H. Jensen and M. S. Gordon, J. Am. Chem. Soc. 117, 8159 (1995).

${ }^{13}$ (a) J. Casado, J. T. López-Navarrete, and F. J. Ramírez, J. Raman Spectrosc. 26, 1003 (1995); (b) J. Casado, J. T. López-Navarrete, and F. J. Ramírez, Spectrochim. Acta A 51, 2347 (1995).

${ }^{14}$ D. Rinaldi and J. L. Rivail, Theor. Chim. Acta 32, 57 (1973).

${ }^{15}$ (a) S. Miertus, E. Scrocco, and J. Tomasi, Chem. Phys. 55, 117 (1981); (b) R. Cammi and J. Tomasi, J. Comput. Chem. 16, 1449 (1995); (c) E. L. Coitiño, J. Tomasiand, and R. Cammi, J. Comput. Chem. 16, 20 (1995).

${ }^{16}$ C. J. Cramer and D. G. Truhlar, Science 256, 213 (1992).

${ }^{17}$ A. Klamt and G. Schuurmann, J. Chem. Soc. Perkin Trans. 2, 799 (1993).

${ }^{18}$ R. G. Parr and W. Yang, in Density Functional Theory of Atoms and Molecules (Oxford University Press, New York, 1989).

${ }^{19}$ (a) V. Barone, C. Adamo, and F. Lelj, J. Chem. Phys. 102, 364 (1995); (b) D. T. Nguyen, A. C. Scheiner, J. W. Andzelm, S. Sirois, D. R. Salahub, and A. T. Hagler, J. Comput. Chem. 18, 1609 (1997).

${ }^{20}$ A. G. Császár, J. Physiol. (London) 100, 3541 (1996).

${ }^{21}$ V. Barone and C. Adamo, Int. J. Quantum Chem. 61, 429 (1997).

${ }^{22}$ G. Rauhut and P. Pulay, J. Physiol. (London) 99, 3093 (1995).

${ }^{23}$ (a) P. C. Hariharan and J. A. Pople, Theor. Chim. Acta 28, 213 (1973); (b) T. Clark, J. Chandrasekhar, G. W. Spitznagel, and P. v. R. Schleyer, J. Comput. Chem. 4, 294 (1983).

${ }^{24}$ (a) A. D. Becke, Phys. Rev. A 38, 3098 (1988); (b) J. P. Perdew and Y. Wang, Phys. Rev. B 45, 13244 (1992).

${ }^{25}$ G. N. Merrill and S. R. Kass, J. Physiol. (London) 100, 17465 (1996).

${ }^{26}$ H. B. Schlegel, J. Comput. Chem. 3, 214 (1982).

${ }^{27}$ C. Peng, P. Y. Ayala, H. B. Schlegel, and M. J. Frish, J. Comput. Chem. 17, 49 (1996).

${ }^{28}$ J. L. Rivail and D. Rinaldi, Chem. Phys. 18, 233 (1976).

${ }^{29}$ J. L. Rivail, D. Rinaldi, and M. F. Ruiz-López, in Theoretical and Computational Models for Organic Chemistry, edited by S. J. Formosinho, L. Arnaut and I. Csizmadia (Kluwer, Dodrecht, 1991).

${ }^{30}$ J. Bertrán, M. F. Ruiz-López, D. Rinaldi, and J. L. Rivail, Theor. Chim. Acta 84, 181 (1992).

${ }^{31}$ D. Rinaldi, J. L. Rivail, and N. Rguini, J. Comput. Chem. 13, 675 (1992). 
${ }^{32}$ X. Assfeld and D. Rinaldi, in AIP Conference Proceedings, ECCC 1, edited by F. Bernardi and J. L. Rivail (AIP, Woodbury, NY, 1994).

${ }^{33}$ (a) L. Onsager, J. Am. Chem. Soc. 58, 1486 (1936); (b) M. W. Wong, M. J. Frisch, and K. B. Wiberg, J. Am. Chem. Soc. 113, 4776 (1991).

${ }^{34}$ F. J. Ramírez, E. Silla, and I. Tuñón (unpublished).

${ }^{35}$ M. J. Frisch, G. W. Trucks, H. B. Schlegel, P. M. W. Gill, B. G. Johnson, M. A. Robb, J. R. Cheeseman, T. Keith, G. A. Petersson, J. A. Montgomery, K. Raghavachari, M. A. Al-Laham, V. G. Zakrzewski, J. V. Ortiz, J. B. Foresman, J. Cioslowski, B. B. Stefanov, A. Nanayakkara, M. Challacombe, C. Y. Peng, P. Y. Ayala, W. Chen, M. W. Wong, J. L. Andres, E. S. Reploge, R. Gomperts, R. L. Martin, D. J. Fox, J. S. Binkley, D. J. Defrees, J. Baker, J. P. Stewart, M. Head-Gordon, C. Gonzalez, and J. A. Pople, GAUSSIAN 94, Revision D.3 (Gaussian, Inc., Pittsburgh, PA, 1995).

${ }^{36}$ D. Rinaldi and R. R. Pappalardo, SCRFPAC, QCPE Indiana University, Bloomington, IN, 1992. Program number 622.

${ }^{37}$ P. Pulay, G. Fogarasi, F. Pang, and J. R. Boggs, J. Am. Chem. Soc. 101, 2550 (1979).

${ }^{38}$ E. B. Wilson, J. Chem. Phys. 7, 1047 (1939).

${ }^{39}$ A. G. Császár, J. Mol. Struct. 346, 141 (1995).

${ }^{40}$ As we show in Ref. 9 there is another conformer of neutral glycine that is $0.73 \mathrm{kcal} / \mathrm{mol}$ more stable in the gas phase at the MP $2 / 6-31+\mathrm{G}^{* *}$ than that presented in Fig. 1, but in solution the energy difference is $-2.67 \mathrm{kcal} / \mathrm{mol}$, at the same computational level, being the cyclic conformer of Fig. 1 more stable. In the case of alanine the energy difference in solution is $-1.02 \mathrm{kcal} / \mathrm{mol}$ at the $\mathrm{MP} 2 / 6-31+\mathrm{G}^{* *}$ level. The energy barriers of the interconversion processes between both neutral conformers have been not considered.

${ }^{41}$ P. D. Godfrey and R. D. Brown, J. Am. Chem. Soc. 117, 2019 (1995).

${ }^{42}$ R. F. Frey, J. Coffin, S. Q. Newton, M. Ramek, V. K. W. Cheng, F. A.
Momany, and L. Schäfer, J. Am. Chem. Soc. 114, 5369 (1992).

${ }^{43}$ G. Wada, E. Tamura, M. Okina, and M. Nakamura, Bull. Chem. Soc. Jpn. 55, 3064 (1982).

${ }^{44}$ P. J. Haberfield, J. Chem. Educ. 57, 346 (1980).

${ }^{45}$ M. J. Locke and R. T. McIver, Jr., J. Am. Chem. Soc. 105, 4226 (1983).

${ }^{46}$ I. Tuñón, E. Silla, C. Millot, M. T. C. Martins Costa, and M. F. RuizLópez (unpublished).

${ }^{47}$ J. A. Pople, R. Krishnan, H. B. Schlegel, D. J. DeFrees, J. S. Binkey, M. J. Frisch, R. F. Whiteside, R. F. Hout, and W. J. Hehre, Int. J. Radiat. Oncol., Biol., Phys. 15, 269 (1981).

${ }^{48}$ G. Fogarasi and P. Pulay, Annu. Rev. Phys. Chem. 35, 191 (1984).

${ }^{49}$ M. Kakihana, M. Akiyama, T. Nagumo, and M. Z. Okamoto, Z. Naturforsch. Teil A 43, 774 (1988).

${ }^{50}$ M. Tsuboi, T. Takenishi, and A. Naramura, Spectrochim. Acta 18, 271 (1963).

${ }^{51}$ K. Furik, V. Mohazed, M. Bonifazic, and I. Stefanic, J. Mol. Struct. 267, 39 (1982).

${ }^{52}$ M. Takeda, R. E. S. Iavazzo, D. Garfinkel, I. H. Scheinberg, and J. T. Edsall, J. Am. Chem. Soc. 80, 3813 (1958).

${ }^{53}$ S. A. S. Ghazanfar, D. V. Myers, and J. T. Edsall, J. Am. Chem. Soc. 86, 3439 (1964)

${ }^{54}$ J. S. Alper, H. Dothe, and D. F. Coker, Chem. Phys. 153, 51 (1991).

${ }^{55}$ M. Diem, P. L. Polavarapu, M. Oboodi, and L. A. Nafie, J. Am. Chem. Soc. 104, 3329 (1982).

${ }^{56}$ J. F. Pearson and M. A. Slifrin, Spectrochim. Acta A 284, 2403 (1972).

${ }^{57}$ L. J. Bellamy, in Advances in Infrared Group Frequencies (Methuen \& Co., Ltd., Bungay, Suffolk, 1968). 